Gut, 1972, 13, 390-394

\title{
Radioimmunoassay of carcinoembryonic antigen in serum of normal subjects and patients with colonic carcinoma'
}

\author{
MARTIN S. KLEINMAN² AND MICHAEL D. TURNER \\ From the Isaac Gordon Laboratory for Gastrointestinal Research, University of Rochester, School of Medicine \\ and Dentistry, Rochester, New York
}

SUMMARY Sera from 14 normal subjects and 43 patients with colonic carcinoma were evaluated for the presence of carcinoembryonic antigen (CEA). Inhibiting material which behaved in the assay in a similar manner to CEA was found in normal serum at concentrations below $2.8 \mathrm{ng} / \mathrm{ml}$. Its nature has not so far been established. Thirty-eight of the 43 patients with colonic carcinoma showed levels of serum CEA in excess of $2.8 \mathrm{ng} / \mathrm{ml}$. The concentration of CEA in serum was correlated with the extent of the disease as classified by a staging procedure similar to that of Dukes (1932). Examination of a small number of specimens of colonic carcinoma and normal colonic mucosa suggested that the concentration of CEA in different adenocarcinomata may vary, and that traces of cross-reacting material may be found in some normal mucosae.

Previous reports have described the preparation of absorbed rabbit antisera (anti-CEA), which react with antigens (CEA) extractable from human colonic carcinoma (Gold and Freedman, 1965a, 1965b; Kleinman, Harwell, and Turner, 1971), and the production and preparation of radioiodinated antigen ( ${ }^{125}$ ICEA), and its use in a radio immunoassay for CEA (Thompson, Krupey, Freedman, and Gold, 1969; Turner, Olivares, Harwell, and Kleinman, 1972). This radioimmunoassay has shown that the serum of many patients with colonic carcinoma of undefined extent contains material resembling carcinoembryonic antigen. The present communication describes the application of the assay to the study of sera from normal subjects and patients with colonic carcinoma classified according to the extent of the disease. The assay was also applied to a small number of specimens of normal colonic mucosa and colonic adenocarcinoma.

\section{Materials and Methods}

Carcinoembryonic antigen was prepared as pre-

'Supported by grant 5-TO-1-AM-05177 from the National Institute of Arthritis and Metabolic Diseases, USPHS, by a grant from the Monroe County Cancer and Leukemia Association, by the General Research Support Grant, RR 05403, and Center Grant CA 11198 from the National Cancer Institute.

'Advanced clinical fellow of the American Cancer Society.

Received for publication 2 March 1972. viously described (Kleinman et al, 1971). After iodination, the ${ }^{125}$ ICEA was submitted to $\mathrm{CsCl}$ gradient ultracentrifugation. The second ultracentrifuge peak of ${ }^{125}$ ICEA was used for radioimmunoassay with rabbit IgG anti-CEA (Turner et al, 1972).

Venous blood was obtained from 14 normal subjects and preoperatively from 43 patients with carcinoma of the colon scheduled for surgery. After allowing the blood to coagulate at room temperature for 30 minutes the serum was removed by centrifugation and stored at $-20^{\circ} \mathrm{C}$. Five $\mathrm{ml}$ of serum was added to an equal volume of $2 \mathrm{M} \mathrm{HC10}_{4}$ mixed on a vortex mixer and, after standing for 30 minutes at room temperature, centrifuged. The supernatant was removed, dialysed in Visking sac against running tap water at $4^{\circ} \mathrm{C}$ for 36 hours and then against four changes of distilled water for a further 36 hours. The contents of the sac were carefully removed, the sac was washed with distilled water, the washings were added to the previously removed material, and the mixture was lyophilized.

The lyophilized powder was dissolved in $0.2 \mathrm{ml}$ of a 1:100 dilution of normal human serum in borate buffer, $p \mathrm{H} 8.4$ (1:100 normal human serum). To this was added $0.1 \mathrm{ml}$ of antibody solution containing $6 \mu \mathrm{l}$ of 1:500 rabbit anti-CEA and $94 \mu 1$ of $1: 10$ normal human serum. After standing for eight hours at $4^{\circ} \mathrm{C}, 4 \mathrm{ng}$ of ${ }^{125} \mathrm{ICEA}$ in $0.1 \mathrm{ml} 1: 100$ normal human serum was added to each tube. After 20 
hours at room temperature the radioactivity was measured in a Nuclear Chicago automatic gamma counter, and $0.4 \mathrm{ml}$ of saturated ammonium sulphate was added to each tube which stood in ice. After one hour the tubes were centrifuged for 15 minutes at $2400 \mathrm{~g}$ and the supernatant was aspirated with a bent Pasteur pipette. Aliquots, each of $0.4 \mathrm{ml}$, of $50 \%$ saturated ammonium sulphate, were added to each precipitate which was resuspended and recentrifuged. The radioactivity of the precipitate was measured and was expressed as a percentage of that in the original solution. A standard curve was prepared using, in place of the lyophilized powder, $0 \cdot 2 \mathrm{ml}$ aliquots of 1:100 NHS to which had been added unlabelled CEA in amounts from 1 to 100 ng.

Perchloric acid extracts were made from resected specimens of colonic carcinoma and normal colonic mucosa in the standard manner. After removal of the perchloric acid the speciments were lyophilized and submitted to radioimmunoassay. The protein content of the extracts was determined by the method of Lowry, Rosebrough, Farr, and Randall (1951). The CEA content of each specimen was then expressed as nanograms of CEA per microgram of protein.

In order to determine the effect of the perchloric acid extract of serum on the assay procedure $2 \cdot 5$, 5.0 , and $10 \mathrm{ml}$ quantities of the same normal human serum were extracted with equal volumes of $\mathrm{HClO}_{4}$, dialyzed and lyophilized. These were then assayed by the standard procedure and the results compared with the standard curve.

To measure the efficiency of the perchloric acid extraction procedure, known amounts of CEA from 1 to $100 \mathrm{ng}$ were added to separate $5 \mathrm{ml}$ aliquots of the same normal human serum. These were then extracted with perchloric acid, dialyzed, and lyophilized in the usual manner. Another series of $5 \mathrm{ml}$ aliquots of the same serum was prepared. These were extracted with perchloric acid, dialyzed and lyophilized and to each powder a known amount of CEA was added. All specimens were then assayed and the results of the two series compared.

The stage of the disease in the 43 patients with colonic carcinoma was assessed from the surgical findings at laparotomy and from pathological examination of the resected specimens. The stage of the disease was classified according to a modification of the system which Dukes (1932) introduced for cancer of the rectum. Stage A cancer is a mucosal tumour which does not involve the serosa, stage $B$ is a tumour involving the colonic serosa, stage $C$ is a tumour with local lymph node involvement, and stage $D$, which was not included in the original classification, carcinoma with distant metastases.

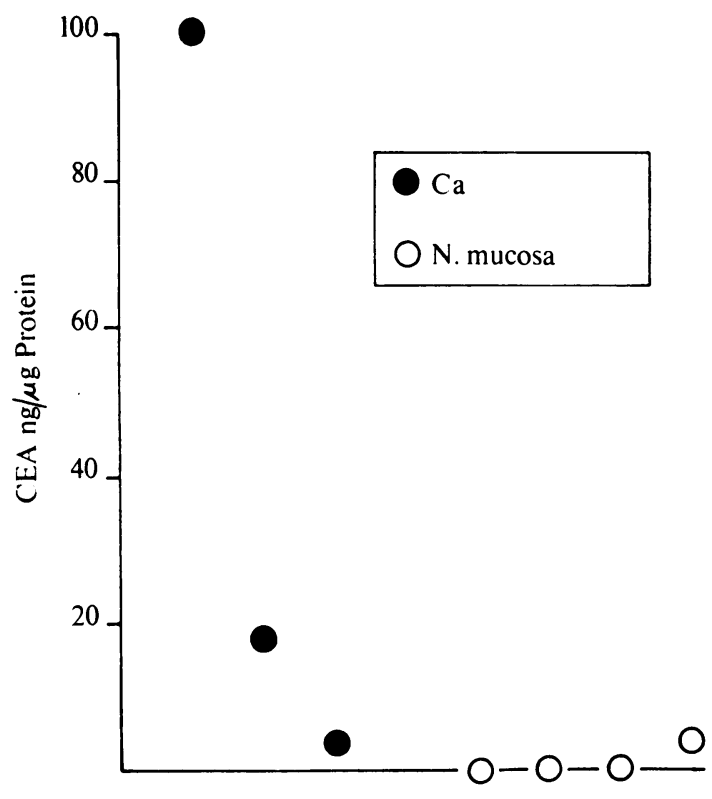

Fig. 1 Carcinoembryonic antigen in perchloric acid extracts of normal human colonic mucosa (open circles) and colonic adenocarcinomata (solid dots). Note that the three extracts from the adenocarcinomata contained detectable CEA, but in different concentrations. One of the four extracts from normal mucosa contained a small amount of 'assayable CEA' in a concentration similar to that of one of the tumours.

\section{Results}

ASSAY OF NORMAL COLONIC MUCOSA AND COLONIC ADENOCARCINOMA

Four specimens of normal mucosa were assayed: three of these produced no detectable inhibition in the assay system and one behaved as if it contained $4.0 \mathrm{ng}$ CEA per $\mu \mathrm{g}$ protein. Three tumour extracts when assayed appeared to contain CEA at concentrations of 100,19 , and $4.0 \mathrm{ng} / \mu \mathrm{g}$ protein (Fig. 1).

EFFECT OF NORMAL SERUM IN ASSAY SYSTEM Perchloric acid extracts made from $5 \mathrm{ml}$ aliquots of serum from 14 apparently healthy males and nonpregnant females in their third and fourth decades inhibited the precipitation of ${ }^{125}$ ICEA when tested in the assay system. The mean value for the 14 specimens was equivalent to $1.6 \mathrm{ng}$ CEA per $\mathrm{ml}$ serum with a standard deviation of $0.58 \mathrm{ng} / \mathrm{ml}$.

The slight inhibition observed with the normal sera raised the question of whether it might be due to traces of CEA in normal serum or to some other substances which reacted in the assay system. A 
normal serum specimen which, when assayed, gave a value of $2.5 \mathrm{ng} / \mathrm{ml}$ was therefore obtained in large volume and tests were made of the inhibitory activity of lyophilized perchloric acid extracts of $2.5 \mathrm{ml}, 5 \mathrm{ml}$, and $10 \mathrm{ml}$ amounts of this serum. The three quantities of extracted serum showed activity in the assay system equivalent to $2 \cdot 8,2 \cdot 5$, and $2 \cdot 5 \mathrm{ng} \mathrm{CEA} / \mathrm{ml}$ respectively (Fig. 2).

EXTRACTION OF CEA ADDED TO NORMAL SERUM The average recovery of CEA added to normal serum in concentrations of 1 to $20 \mathrm{ng} / \mathrm{ml}$ after extraction with $\mathrm{HClO}_{4}$ and assay in the standard procedure was $77 \%$ with a range of 62 to $100 \%$. Duplicate assays showed good reproducibility (Fig. 3).

\section{CEA IN SERUM}

The mean serum CEA level in the 14 healthy subjects was $1.6 \mathrm{ng} / \mathrm{ml}$ (SD $0.58 \mathrm{ng} / \mathrm{ml}$ ) and in the 43 carcinoma patients $11 \cdot 2 \mathrm{ng} / \mathrm{ml}$. The patients with stage A disease had a mean serum CEA of 5.9 $\mathrm{ng} / \mathrm{ml}$, those with stage B a mean CEA of $7.5 \mathrm{ng} / \mathrm{ml}$, those with stage $C$ a mean CEA of $11.9 \mathrm{ng} / \mathrm{ml}$, and patients with stage $D$ disease a mean CEA of 16.5 $\mathrm{ng} / \mathrm{ml}$. The values of serum CEA in the patients with stage $D$ disease were significantly different from those of patients with disease in stages A and B $(P<0.05)$. The difference in serum CEA of the total group of 43 patients with colonic cancer and that of the normal subjects was also significant $(\mathrm{P}<0.01)$.

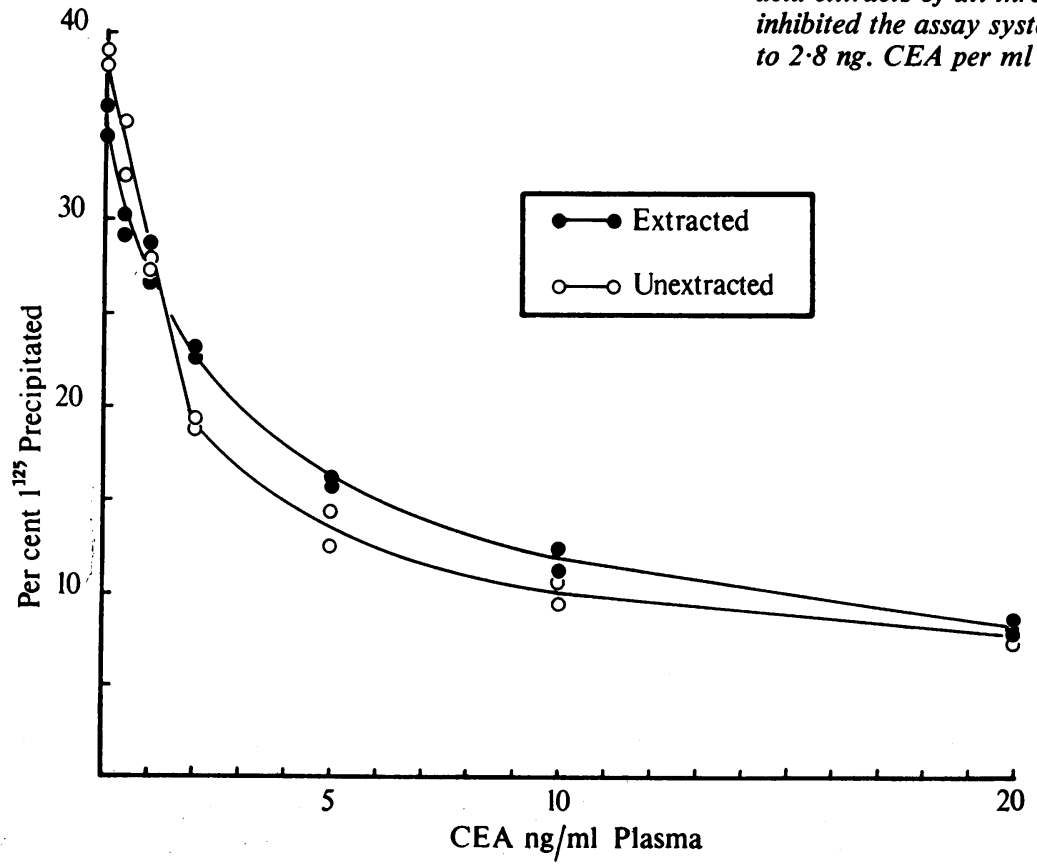

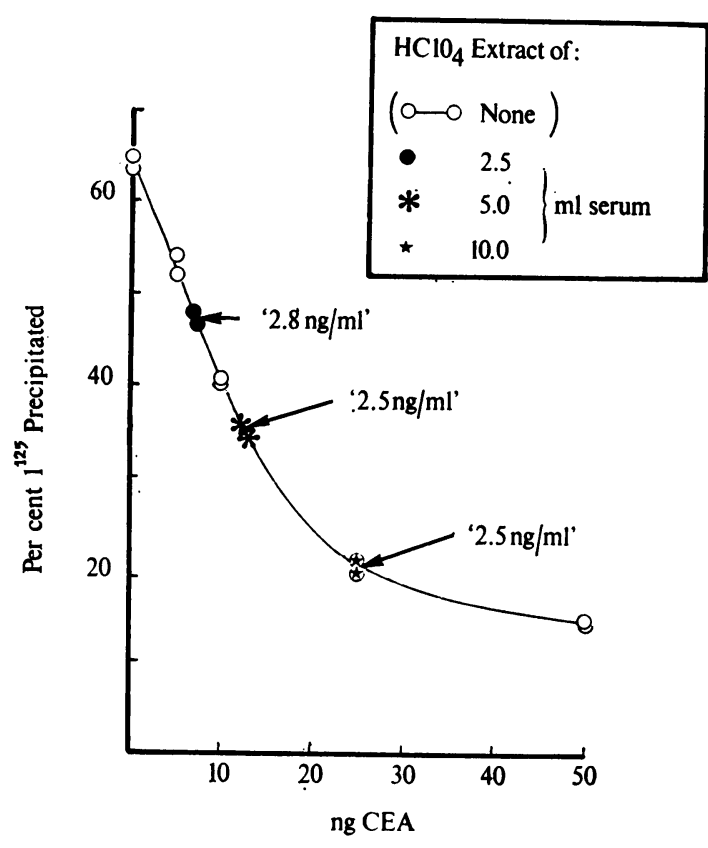

Fig. 2 Perchloric acid extracts made in duplicate from $2.5 \mathrm{ml}, 5.0 \mathrm{ml}$, and $10.0 \mathrm{ml}$ of the same normal serum assayed by the standard technique. Ordinate shows percentage of radioactivity precipitated as ${ }^{125}$ ICEA. Open circles and the line joining them show standard inhibition curve produced by addition of the quantities of CEA shown on the abscissa. Note that the perchloric acid extracts of all three quantities of normal serum inhibited the assay system as if they contained from 2.5 to $2 \cdot 8 \mathrm{ng}$. CEA per ml of serum.

Fig. 3 Recovery of CEA added to serum after extraction and assay. Ordinate shows percentage of radioactivity as ${ }^{125}$ ICEA precipitated in standard assay system. Carcinoembryonic antigen in the quantities shown on the abscissa was added to $5 \mathrm{ml}$ aliquots of serum and then extracted with perchloric acid (solid dots) or it was added in the quantities shown to previously prepared perchloric acid extracts of $5 \mathrm{ml}$ quantities of the same serum (open circles). Comparison of the two inhibition curves shows that $62-100 \%$ of the CEA added to serum was recovered. 


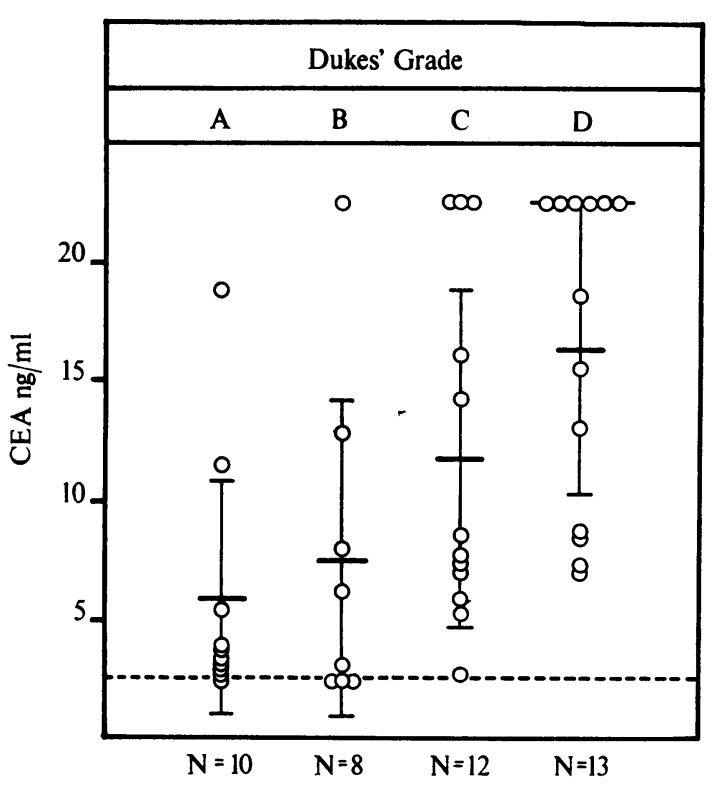

Fig. 4 Serum CEA in 43 patients with colonic carcinoma classified according to the extent of the disease. Interrupted horizontal line shows upper limit of normal for serum CEA $(2 \cdot 8 \mathrm{ng} / \mathrm{ml})$. Note that the majority of patients with colonic cancer show elevated serum levels of CEA and that this appears to increase with the extent of the disease. Open circles show values of CEA in individual patients; heavy horizontal bars are the means for each of the four groups. The range shown is $\pm 1 S D$.

\section{Discussion}

Three of the four specimens of colonic mucosa did not appear to contain CEA when assayed in the standard manner. The fourth specimen, however, behaved as if it contained a trace of carcinoembryonic antigen. Indeed the value of $4 \mathrm{ng} \mathrm{CEA} / \mu \mathrm{g}$ of protein was the same as that found in one of the three carcinomata examined. The other two carcinomata, however, showed much higher concentrations of carcinoembryonic antigen. Too few specimens were tested for any definite conclusions but the results suggest that the concentration of CEA may vary in different tumours. The three tumours tested we: all adenocarcinomata and histologically appeared similar. Further studies are clearly indicated to determine if there is any relationship between the appearance of the tumour and its CEA content. The finding of a trace of CEA activity in one normal mucosal extract is hard to interpret. It may indicate that CEA is indeed present in very low concentrations in normal tissue, as Martin and
Martin (1970) have suggested, or alternatively may represent inhibition of the assay system by some other material.

The upper limit of normal for serum CEA with the assay described here was $2.8 \mathrm{ng} / \mathrm{ml}$. This is close to the value of $2.5 \mathrm{ng} / \mathrm{ml}$ reported by others (Thompson et al, 1969; Moore, Kupchik, Marcon, and Zamcheck, 1971; Lo Gerfo, Krupey, and Hansen, 1971). In the present study 38 of 43 patients $(88 \%)$ with colonic carcinoma had a serum CEA of more than 2.8 $\mathrm{ng} / \mathrm{ml}$. This is similar to the $91 \%$ of positive tests found in patients with colonic carcinoma by Moore et al (1971) who used reagents donated by Gold, and the $85 \%$ positive reported by Lo Gerfo et al (1971) who employed an assay system developed by Hansen, Lance, and Krupey (1971). In the present investigation and those of Moore et al (1971) and Lo Gerfo et al (1971) the frequency of positive serum CEA tests in patients with colonic carcinoma is somewhat lower than that originally reported by Thompson et al (1969). Although no data on the stage of the disease are included in the studies of Thompson et al (1969), of Moore et al (1971), or of Lo Gerfo et al (1971), the discrepancy may be due to the inclusion of more patients with early cancer in the present series and in those of Moore and Lo Gerfo than in the original series of Thompson, since the present study indicates that both the frequency of abnormal serum CEA levels and the concentration of CEA in serum increase with the stage of the disease. This may simply indicate that greater masses of tumour produce more carcinoembryonic antigen. Other mechanisms may, however, be operative.

The relatively low levels of serum CEA seen in many patients with stage A cancer pose some problems in the use of the CEA test as a screening procedure for early cancer. The problem that arises is not that the serum of many stage A patients fails to produce any inhibition at all in the assay system but that many of these sera produce inhibition which falls within the same range as that observed with normal sera. That normal sera do inhibit this assay is clear from the experiments with the perchloric acid extracts of normal serum. These indicate that extracts of normal serum contain material which behaves quantitatively in a manner very similar to CEA itself. They do not of course prove that normal serum contains CEA; indeed the inhibition may be due to some other substances. These experiments and those with the extracts of colon cancer and normal colonic mucosa, however, raise the possibility that minute traces of CEA may occur in normal adult tissues and that the differences observed between normal subjects and patients with cancer are quantitative rather than qualitative as Martin and Martin (1970) suggested previously. The overlap in 
the values for serum CEA found in the normal subjects and many of the stage A cancer patients makes it important to determine the nature of the inhibitory material present in normal serum. If this material proves to be different from CEA and if a simple method can be developed to distinguish between the inhibition produced by normal serum and that due to traces of CEA, it may be possible to detect the vast majority of early cases of cancer of the colon by this technique.

The sera of 48 patients with diseases other than cancer of the colon were assayed by the standard technique. To date insufficient numbers have been studied to draw any firm conclusions on the frequency of abnormal serum CEA tests in other diseases. The data, however, suggest that a proportion of patients with diseases other than cancer of the colon may show minor elevations of serum carcinoembryonic antigen. Moore et al (1971) reported a relatively high frequency of positive serum CEA tests in patients with alcoholic liver disease but Lo Gerfo and his colleagues (1971) found no positive tests in this group of patients with their assay. Moore used antigens and antibodies produced by Gold in Montreal whereas Lo Gerfo employed an antigen which had originally been prepared by fractionation of some material obtained from Gold. In the present investigation the antigen was made in this laboratory (Turner et al, 1972), and, although it was prepared by techniques similar to those of Gold and Freedman $(1965,1965 \mathrm{a})$, it was further purified by a number of additional separation procedures. The antisera used in the three studies were also different. It must beremembered that CEA is a moderately large molecule; indeed it may be more properly regarded as a class of molecules with similar properties rather than a single substance. It is likely that these contain a number of distinct antigenic sites each of which may give rise to antibodies in experimental animals. It is possible that some of the antigenic determinants on the CEA molecule occur on other glycoproteins (Turner et al, 1972) to be found in normal human tissue or in tissue affected by diseases including neoplasia. Others of the antigenic sites on CEA may be more specific for this molecule. Lo Gerfo et al (1971) found that their antiserum would react with serum antigens in patients with a variety of neoplastic diseases, including carcinoma of the lung, breast, bladder, and stomach as well as the colon. This was in contrast to the previous reports of Thompson et al (1969) whose antiserum gave positive results only with patients with gastrointestinal malignancies. Lo Gerfo and his colleagues concluded that there is a tumour-associated antigenic site on CEA which is common to tumours of entodermal and non-entodermal origin. Analogous types of common antigenic determinants have been reported by Edynak, Old, Vrana, and Lardis (1970) in constituents of breast and thyroid carcinoma, sarcoma of bone, muscle and nerve, and foetal tissue from a variety of species. Similarly, Zilber (1962) found that antisera to gastric carcinoma could react with neoplasms from the lung and gastrointestinal tract. It is thus possible that many different antisera may be prepared all of which react with CEA molecules but at antigenic sites of differing specificity. The cross-reactivity of such antisera with other glycoproteins may vary considerably, some being more specific for certain tumours than others. When used in clinical assays, the results with different sera may therefore show some variability. Such problems can be elucidated only by more careful studies of the structure of CEA preparations and their antigenic determinants.

We gratefully acknowledge the assistance of Lee Harwell and Telba A. Olivares.

\section{References}

Dukes, C. E. (1932). The classification of cancer of the rectum. $J$. Path. Bact., 35, 323-332.

Edynak, E. M., Old, L. J., Vrana, M., and Lardis, M. (1970). A fetal antigen in human tumors detected by an antibody in the serum of cancer patients. (Abstr.) Proc. Amer. Ass. Cancer Res., 11, 22.

Gold, P., and Freedman, S. O. (1965a). Demonstration of tumorspecific antigens in human colonic carcinomata by immunological tolerance and absorption techniques. J. exp. Med., 121, 439-462.

Gold, P., and Freedman, S. O. (1965b). Spzcific carcinoembryonic antigens of the human digestive system. J. exp. Med., 122, 467-481.

Hansen, H. J., Lance, K. P., and Krupey, J. (1971). Demonstration of an ion sensitive antigenic site on carcinoembryonic antigen using zirconyl phosphate gel. Clin. Res., 19, 143.

Lo Gerfo, P., Krupey, J., and Hansen, H. J. (1971). Demonstration of an antigen common to several varieties of neoplasia: assay using zirconyl phosphate gel. New Engl. J. Med., 285, 138-141.

Lowry, O. H., Rosebrough, N. J., Farr, A. L., and Randall, R. J. (1951). Protein measurement with the folin phenol reagent. J. biol. Chem., 193, 265-275.

Kleinman, M. S., Harwell, L., and Turner, M. D. (1971). Studies of colonic carcinoma antigens. Gut, 12, 1-10.

Martin, F., and Martin, M. S. (1970). Demonstration of antigens related to colonic cancer in the human digestive system. Int. J. Cancer, 6, 352-360.

Moore, T. L., Kupchik, H. Z., Marcon, N., and Zamcheck, N. (1971). Carcinoembryonic antigen assay in cancer of the colon and pancreas and other digestive tract disorders. Amer. J. dig. Dis., 16, 1-7.

Thompson, D. M. P., Krupey, J., Freedman, S. O., and Gold, P. (1969). The radioimmunoassay of circulating carcinoembryonic antigen of the human digestive system. Proc. nat. Acad. Sci. (Wash.) 64, 161-170.

Turner, M. D., Olivares, T. A., Harwell, L. and Kleinman, M. S. (1972). Further purification of perchlorate-soluble antigens from human colonic carcinomata. J. Immunol., in press (May, 1972).

Zilber, L. A. (1962). Study of the tumor specificity of gastric cancer tissue. Ann N.Y. Acad. Sci., 101, 264-270. 